CASE OF

\title{
POPLITEAL ANEURISM,
}

\begin{abstract}
CURED BY COMPRESSION OF THE FEMORAL ARTERY IN THE UPPER THIRD OF ITS COURSE, THE PATIENT DYING FIVE MONTHS AFTER OF ANEURISM OF THE ABDOMINAL AORTA, WITH AN ACCOUNT OF THE DISSECTION OF THE AFFECTED LIMB.
\end{abstract}

\author{
BY \\ J. MONRO, M.D., \\ Batallion SURGEON, COLDSTREAM GUARDS.
}

Received Jan. 7th.-Read Jan. 11th, 1853.

The following case, being the second in which the cure of a popliteal aneurism by compression of the femoral artery, has been accomplished in the Hospital of the Coldstream Guards, is interesting, not only from the circumstance of its adding another to the already numerous list of instances in which this plan has been successful, but from the valuable practical fact which seems to be proved, viz., that a much smaller amount of pressure on the artery communicating with the sac than was formerly judged necessary, will suffice for the cure of the disease. This therefore being established, the chief difficulty which prevents pressure from being steadily applied in practice, arising from the severe pain it generally causes, is materially lessened; the chances of sloughing of the integuments are diminished, and a plan of cure is adopted which is more consonant to the natural process; and consequently a safer one. I am well aware that it will be objected to the practice of not entirely impeding the flow of blood into the aneurism, that it is tedious, and that cases are on record where the sac has ceased to pulsate in three days, and even less when the 
tourniquet has been removed, after having been applied for that time, so as to entirely stop the current of blood through the artery; but, in my opinion, we cannot too closely imitate the process of nature, which has been so well illustrated by Mr. Hodgson and others; whereby the abrupt change which must follow the cessation of the circulation through the usual channel, from the undeveloped state of the anastomosing vessels, is avoided, a circumstance the more to be borne in mind, considering the tendency to disease, if not the actually diseased state, of other portions of the arterial system in those in whom one aneurism already exists.

It is with these views that I have now the honour of submitting the accompanying Case to the consideration of the Society :

Case.-Drummer W. Keynes, æt. 23, of a spare and delicate habit of body, whose health had been evidently impaired, walked to the hospital on the 19th April, 1852, complaining of severe pain in the calf of the left leg, which was also a good deal swelled; the veins were dilated. He stated that five days ago, prior to which he had the perfect use of his limb, he had been playing cricket, when he was obliged to desist, owing to the pain he suffered in the situation referred to. Had not remarked any pulsating tumour, but imagined he had met with a sprain. Thinking that it would get better, he had not applied for advice, and had continued his duty since. Finding that the leg became more painful, he now came to the hospital.

The nature of the disease was at once evident on examining the popliteal space.

A large pulsating tumour, about the size of a small orange, filled that situation. It had all the diagnostic signs of aneurism, more particularly the bellows-sound heard on the application of the stethoscope. The sac admitted of being partially emptied by pressure, but returned to its former dimensions when that was removed. The colour of the integuments was natural. The femoral 
artery was examined, with the view of ascertaining whether any other aneurism existed. The artery pulsated soundly from Poupart's ligament to the spot where it enters the tendinous canal of the adductor magnus. The chest was also examined, and found in a healthy condition. The sounds of the heart indicated no disease, nor was there any morbid symptom along the course of the abdominal aorta.

On referring to previous admissions, it was found that he had been many times in hospital, not, however, for any lengthened period, but for slight catarrhs to which he was subject. He had been treated for venereal sores five times; once only had mercury been administered, and then merely for ten days.

The successful issue of a former case, the particulars of which are published in the 'Transactions' of this Society, and which was treated by my colleagues, Messrs. Greatrex and Robinson, encouraged me to make a similar attempt for the cure of the disease, particularly as circumstances seemed to favour the plan. The thigh not being muscular, the artery was easily compressed. With the concurrence of my colleagues and Mr. Holt, who was present, I applied an instrument, invented, I believe, by Mr. Phillips. It was fixed to the pelvis and thighs, and more calculated to steady the pressure which is made by screw pads, constructed to shift up and down the thigh, by an ingenious mechanism, as may be desired. The pressure was at first made immediately below Poupart's ligament, and then only moderately. This was chosen as an eligible situation, especially as there were no enlarged glands. In about an hour and a half the patient complained of much pain, and towards evening became so feverish that it was necesary to remove the apparatus. Being persuaded that this was owing more to alarm than to the pressure employed, which was only moderate, and in order to reconcile him to it, I began next day to make manual pressure a little below the origin of the profunda. This was easily effected by the assistance of several intelligent convalescents, who were shown the 
manner of doing it, and who relieved one another in this duty. The artery was compressed to such a degree only as to allow the sac to pulsate feebly. For the first three days this plan was followed for eight hours during the day only. The patient did not complain of the pain, nor did it seem to produce any feverishness. This being the case, he said he thought he could bear the pressure with the clamp tourniquet. This was, therefore, placed on the thigh, the same principles being attended to in its use. It was removed at night under the impression that it would almost certainly be displaced before the patient became accustomed to it. Finding that it was borne more easily than was expected, the instrument was kept on during the night also from the 26th.

The pressure was not always made in the same place. When there appeared to be any tendency to excoriation of the skin, the pad was shifted either higher up or lower down as the case might be. The report of the 30th states that no pain or feverishness had been occasioned by the instrument; the sac had become harder, and sensibly diminished in size.

The œdema of the calf was less; and he complained no more of pain in that situation. The temperature of the affected limb was like the other. Two of the articular arteries were perceived pulsating over the inner condyle of the femur and head of the tibia. The pulse was 70 . Neither the dorsal artery of the foot nor the posterior tibial could be felt. On the $3 \mathrm{~d}$ of May all had gone on well since last report, the patient bearing the pressure of the tourniquet without suffering. The pulsation of the aneurism had become feebler; the instrument having been removed for a few minutes to ascertain this. The œdema of the calf had diminished, and there was no pain in that situation.

On the 6th, the sac ceased to pulsate, although no greater degree of pressure was used. With the view of finding whether this state would continue, the tourniquet was taken off. The sac did not pulsate for an hour 
afterwards; but, at the expiration of that time, it began to do so feebly. The instrument was, therefore, re-applied, and pressure made as before. The sac had continued to shrink since last report, and become more solid.

The measurement around the joint had diminished from $16 \frac{1}{4}$ to $14 \frac{1}{2}$ inches. On the 8 th, the pulsation in the sac did not return when the tourniquet was removed. It had ceased entirely. The instrument was, therefore, laid aside.

All that was considered necessary to be done now was to keep the patient from using the limb for a short time. He went on favorably from this date: the absorption of the contents of the aneurism proceeded; the functions of the limb were restored; its appearance did not differ from the other; and the anastomosing vessels had become more developed. The femoral artery was ascertained to be pervious to the tendinous canal; but the pulsation of the dorsal artery of the foot and posterior tibial could not be felt. He was not allowed to leave his bed till the $2 \mathrm{~d}$ of June, when the sac had contracted so much that there seemed to be little risk of allowing him to walk about. He gradually acquired the perfect use of the limb, and was dismissed to his duty on the $2 \mathrm{~d}$ of July, some thickening only being felt around the remains of the popliteal artery; but the pulsation of the posterior tibial and dorsal artery of the foot could not be perceived. He continued to do his duty well till the 9th of November, when a small abscess formed over the patella of the leg which had been affected. He remained a few days in hospital with this, and was dismissed.

On the 19th of the same month, he was again admitted with severe pain in the loins and abdomen, a sense of coldness and numbness of lower extremities, small and quick pulse, and the general aspect sunk and haggard. On inquiry, it was found that he had given way to intemperate habits on leaving the hospital. The cause of the symptoms was immediately discovered to be an aneurism of the abdominal aorta about the situation of the cœliac artery. It 
had formed subsequently to his dismissal from hospital in July. The tumour appeared to be a little larger than the closed fist, and of an irregular oblong shape. The stethoscope left no doubt as to its nature. Such being the case, only palliative remedies were given, with the view of allaying his sufferings. Opiates and the mildest diet were tried. He lingered in great suffering till the 10th December, when he died rather suddenly from the rupture of the sac-the day before the patient having felt extremely faint and low. The post-mortem examination confirmed the diagnosis. The heart was sound in every respect, also the aorta, which was free from disease except in the short space between the cœliac axis and superior mesenteric arteries, where a large sac of the shape mentioned above was found. The walls of the sac were very thin, apparently chiefly condensed cellular substance. The openings into it were two, of which one about the size of a shilling had probably been a rupture of the coats of the artery, the edges being partially rounded and partially ragged. The sac was filled with a dense coagulum; several pounds of blood were found extravasated in the cavity of the abdomen. $A$ wax and tallow injection was thrown into the common iliac artery of the limb which had been affected with aneurism, and the following facts were ascertained:

The femoral and popliteal arteries were of the natural size, and pervious until opposite the centre of the popliteal space. The profunda and its branches were much enlarged. Slight thickening was all that remained of the sac, beneath which the artery was obliterated down to its division into the anterior and posterior tibial branches. The anterior tibial was enlarged to the size of the posterior tibial - the latter of the usual size-the peroneal larger than usual. The muscular branches given off by the popliteal to the semi-membranosus, vastus externus, and biceps, larger than generally found. The ramus anastomoticus magnus three times its ordinary size, and dividing into three considerable branches soon after leaving the trunk, any one of which was rather larger than the normal trunk; the inner- 
most passing through the vastus internus to the patella; the second, in front of the tendon of the adductor magnus; the third, behind it, anastomosing in the neighbourhood of the patella with the inferior articular and recurrent tibial arteries, and with each other. Two superior articular and azygos arteries given off by a common branch just previous to the remains of the sac; these auastomosing freely with the recurrent tibial, and ascending branches from the posterior tibial and peroneal. The sural arteries given off at the point where the artery is obliterated, impervious for half an inch, the rest of their course having been injected in a retrograde direction. A tortuous plexus in the substance of the popliteal and peroneal nerves supplied from the branch to the semi-membranosus, and uniting below with a recurrent branch from the anterior and posterior tibial behind the head of the fibula. Another branch descending from the azygos articular communicated with recurrent branches behind the head of the bone. Besides this, a branch from the azygos passed down between the popliteus and bone, and inosculated with a recurrent branch from the anterior tibial just before that vessel passes through the interosseous membrane. The inferior articular arteries enlarged, the inner inosculating freely with the anastomotica magna; the external, with the recurrent tibial and superior articular of the same side.

The recurrent tibial was the most enlarged of any of the branches; it was equal in size to the radial artery, and anastomosed freely with both articulars and the plexus in the peroneal nerve. The communication between the external and internal articular effected by brauches three times their usual size,-all the communicating branches, especially that in the sciatic nerve, more tortuous than usual. The popliteal vein was obliterated for the space of three inches, probably from the pressure of the sac.

The femoral vein pervious, and nothing of note observed as to its state. The sural veins, from the heads of the gastrocnemius (which lie close on the inner side of the condyles of the femur), were unobstructed. Nothing particular 
remarked in the external and internal saphena. With the exception of there being some adhesion of the pleuræ on the left side of the chest, and a little serum in the pericardium and in the peritoneal cavity, the morbid appearances did not show anything remarkable. 